\title{
The Gangnam Style Phenomenon as a Global Manifestation of Hybridity
}

\author{
HESU YOON* AND HANS SCHATTLE**
}

\begin{abstract}
This article explores the parody videos generated around the world in response to the hit song Gangnam Style as a way of viewing the progression of cultural globalization and hybridity in this era of boundless digital communication. First we outline a framework of hybridity in relation to cultural globalization, with the Gangnam Style phenomenon as an exemplar of hybridization, filled with incongruous words and images that cut across supposedly binary categories and cultural norms. Then, drawing upon a content analysis of the original video and numerous parody videos, we illustrate how the interactive and multidirectional responses to Gangnam Style reveal ways in which bottom-up, user-generated cultural globalization can unfold in practice. The transnational public response to Gangnam Style is noteworthy, as it clearly revealed the potential of interactive platforms, such as YouTube, for creating and sharing online content in an extended virtual conversation across national borders.
\end{abstract}

Keywords: Cultural Globalization, Hybridity, Gangnam Style, Hallyu, Korean Wave, New Media, Parody, YouTube

* Ph.D. Candidate, Stanford University, USA; E-mail: hyoon28@stanford.edu

** Professor, Yonsei University, Seoul, South Korea; E-mail: hschattle@yonsei.ac.kr DOI: 10.16934/isr.18.2.201712.1 


\section{INTRODUCTION}

Five years after its release on YouTube, Gangnam Style remains the world's most-watched online video, with more than 2.9 billion views and 13 million 'likes' as of September 2017. The hit single by South Korean pop artist Psy attracted such a massive global following upon its release in July 2012 that many viewers who continue to post comments online say they still watch the music video simply to check how many views this video has. Indeed, Gangnam Style achieved symbolic status because of the remarkable scope and scale of its truly global viewership. It topped the weekly music charts in more than 30 countries, including Russia, France, Bulgaria, Lebanon, and the United Kingdom. It also won 13 music awards, ranging from the MTV Europe Music Award, for best video in 2012, to the World Music Award, for best song in 2014. Gangnam Style was the first video ever on YouTube to reach and surpass 1 billion views in 2012, and then 2 billion views in 2014; it ranks number one among the most watched YouTube videos for the past 10 years - the first full decade of YouTube's existence (YouTube 2015).

The exceptional status of Gangnam Style becomes even clearer when we look at the list of the ten most watched YouTube videos (Billboard 2015). The only two 'Top 10' videos in any other language are both in Korean, and both from Psy: first, Gangnam Style at number one, and then, at number ten, the follow-up Gentleman, with its remarkably high viewership traced directly back to Gangnam Style. Among the remaining top-ranked videos, eight are in English. The success of Gangnam Style suggests an aspect of cultural globalization distinctive from the other 'Top 10' videos that originated from North America. Noteworthy here is how a song with Korean lyrics and directed quite narrowly at a South Korean audience gained so much global popularity.

The global popularity of Gangnam Style instantly generated worldwide attention - from television shows, newspapers and magazines, to review articles covering its viral dissemination. However, scholarly contributions explaining this phenomenon have emerged mainly among Korean scholars (Jung and Shim 2014; Lee and Kuwahara 2014; Jung 2014). The five-year anniversary of Gangnam Style offers an opportune moment to reflect upon and re-examine what the phenomenon has meant and how it offers a view of the contemporary globalization of culture enabled by social media.

Major discourses surrounding Gangnam Style mainly focus on the success of Gangnam Style as a global hit. The core question is often, "How did Gangnam Style go viral?" with inquiries centered on various factors that plausibly contributed to Psy's success. Some Korean researchers interested in pop culture regard Gangnam Style as an upgraded version of the Korean Wave (Cho 2012; Lee 2012; Cho and Yoon 2013; Nye and Kim 2013; Lee and Kuwahara 2014), while 
others have argued that too much emphasis on the Korean Wave can inhibit a broader perspective within a global context (Park 2013; Hong 2013; Jung 2014). However, the range of possible explanations for the huge success of Gangnam Style is not our primary concern in this article. Instead, we treat Gangnam Style as a case study that reveals some important aspects of cultural globalization today, and we focus on the ways in which everyday people around the world circulated, appropriated, and recombined the elements of Gangnam Style by creating their own parody videos.

In this article, we propose to understand the Gangnam Style phenomenon as hybridization which results from active public participation in the globalizing process, particularly in the realms of culture and communication. Gangnam Style became a phenomenon not only because of the video's distinctiveness but also because of the ways people actively appropriated the original music video across a multitude of conceptions and images. From parodies to flash mobs, Gangnam Style has been reproduced by means of thousands of Internet memes, and this proliferation of online videos elevated Gangnam Style from a mere cultural product to a 'sensation.' The sensation was participatory by nature, since the song attracted worldwide attention not only unto itself but also through a seemingly endless stream of derivative videos that people around the world created and shared, engaging in the process of sensation-making.

Specifically, our objective is to answer the following questions: What are the implications of the Gangnam Style phenomenon for contemporary cultural globalization? What manifestations of hybridity related to cultural globalization do we observe in the feast of Gangnam Style videos? By focusing on the accumulation of internet memes and their meanings, we argue that hybridity - as in the crossing of multiple images, symbols and phrases across more familiar or conventional cultural boundaries - is the key element that characterizes the Gangnam Style phenomenon. First, this article examines the concept of hybridity in relation to cultural globalization, and we argue that the Gangnam Style phenomenon can be explained from a perspective emphasizing globalization as hybridization. We then illustrate in detail how hybridization empirically happens, through the lens of the individual, notable case of Gangnam Style. Within the universe of Gangnam Style related internet memes, we focus particularly upon parody videos.

\section{KOREAN CULTURE GOES GLOBAL? HALLYU 2.0 AND THE GANGNAM STYLE PHENOMENON}

Previous researchers who have studied the Gangnam Style phenomenon have situated it mainly within the context of the Korean Wave (Hong 2013; Jung and Shim 2014; Kuwahara 2014; Lee and Nornes 2015). Hallyu - a term 
synonymous with the Korean Wave - operates as a shorthand term for the public appeal of Korean popular culture overseas (Walsh 2014, 13). Admittedly, scholars distinguish the latter decades of Hallyu epitomized by the success of Gangnam Style in the 2010s from the earlier trends in the 2000s (See Table 2 below). They particularly emphasize the elevated role of new media platforms enabled by the development of digital technology. For example, using the case of Gangnam Style, Sangjoon Lee differentiates Hallyu 2.0 from an earlier version of Hallyu:

K-pop girl groups' uniformity, chogukjeok (transnational) styles, and English language songs - strategically planned, developed, and led by Korean entertainment agencies $\cdots$ - were not able to win the U.S. mainstream audiences' attention, but unexpectedly, deterritorialized virtual communities in social media networks showed their grassroots power, and pushed Hallyu, the Korea Wave, into the new realm of what we call in this book Hallyu 2.0 (Lee 2015, 4).

According to Lee, Hallyu 2.0 is different from Hallyu 1.0 in that it incorporates new mechanisms facilitated by the emergence of new media, and in this regard, Lee also points out how Gangnam Style is different from the usual Hallyu fare because of its accidentality. Its stature as a global hit was not "strategically planned, developed, and led by Korean entertainment agencies," but it "unexpectedly" catapulted to the top of the charts and online viewing trends thanks to "virtual communities in social media networks." Gangnam Style as a legendary hit is not attributable to aggressive marketing campaigns funded by global big capital or state-driven initiatives, in ways more emblematic of many other K-pop hits, but instead traces back to the way the music video gained traction on social networking services such as Facebook and Twitter as well as online platforms such as YouTube that enabled its viral spread in a short time period.

TABLE 1. DiFFERENCES BETWEEN HALLYU 1.0 AND HALLYU 2.0

\begin{tabular}{cccccc}
\hline Type & $\begin{array}{c}\text { Main } \\
\text { Genre }\end{array}$ & $\begin{array}{c}\text { Geographical } \\
\text { Range }\end{array}$ & $\begin{array}{c}\text { Time } \\
\text { Range }\end{array}$ & Characteristic & Main consumer \\
\hline Hallyu 1.0 & Drama & East Asia & $2000 \mathrm{~s}$ & $\begin{array}{c}\text { One-way flow from artist to } \\
\text { fans }\end{array}$ & Middle age group \\
\hline Hallyu 2.0 & Music & World & $2010 \mathrm{~s}$ & Participatory (social media) & Teens, twenties \\
\hline
\end{tabular}

Source: Reconstructed from Hallyu 2.0 (Lee et al., 2015, 16) 
Despite these specific differences, the Korean Wave scholars still understand the Gangnam Style phenomenon as an extension of or as comparable to the global or regional reception of Korean popular culture, namely pop music and television dramas. However, is it really appropriate to understand the Gangnam Style phenomenon as situated within the larger dissemination of Korean popular cultural products around the world? Of course, it is undeniable that the Gangnam Style phenomenon and the Korean Wave are somehow intertwined, but this relationship should not be exaggerated, since the core characteristic of the Gangnam Style phenomenon is in its participatory nature that bloomed out of interactive social media platforms. The reason why the Gangnam Style case is so striking is not because it manifested how Korean cultural products could achieve global success but because it demonstrated the ways in which ordinary people from all over the world actively participated in the process of global sensation-making. Therefore, as shown in Table 3 below, the Gangnam Style phenomenon can be better understood in the context of hybrid digital culture rather than the Korean Wave, with its emphasis on state-driven nationalism or corporate-driven marketization. Thus appropriate points of reference to the Gangnam Style phenomenon would be the viral spread of Harlem Shake in 2013 and Pineapple Pen in 2016, rather than, for example, Girl's Generation or 2PM's success in Asia and beyond.

\section{TABLE 2. COMPARISON OF THE KOREAN WAVE AND THE GANGNAM STYLE PHENOMENON}

\begin{tabular}{ccccc}
\hline Type & Direction & Core Agent & Characteristic & Media \\
\hline The Korean Wave & Top-down & State, Corporations & Nationalism, Marketization & Mass-media \\
\hline Gangnam Style & Bottom-up & Grassroots & Hybridity & New-media \\
\hline
\end{tabular}

Even though YouTube exists as a corporate subsidiary of Internet juggernaut Google and functions as an online platform for mainstream media every bit as much as alternative media (Kim 2012; Jung and Shim 2014), YouTube nevertheless engenders and facilitates bottom-up cultural transmissions, since anyone with basic resources and production skills can upload and share videos at no cost. In this regard, YouTube has opened up a new space in which yesterday's media consumers have become today's media producers. Even though Psy himself is not exactly 'grassroots' - given his high personal wealth and the extensive resources of the Korean entertainment industry backing him up, the process of globally disseminating Gangnam Style sprang up from individual agents - the grassroots: Twitterians and YouTubers. Hence the Gangnam Style case provides a key example of cultural content that did not proceed or flow in one-direction - and especially not from 'the West to the rest' - but unfolded as an interactive process criss-crossing continents. 
This haphazard, bottom-up yet sweeping dissemination makes the Gangnam Style phenomenon unique, especially when compared with other K-pop hit singles. Many K-pop hits are produced with the intent of reaching a global audience; thus the songs and videos are often released in multiple versions - a Korean version as well as English, Chinese, and Japanese versions. K-pop songs are marketed and promoted by huge entertainment companies based in Seoul and backed up by the South Korean government's generous subsidies justified, at least from within, as a driving force to boost the country's exports and the stature of its national economy (Shim 2006; Park 2013; Lee and Nornes 2015). Gangnam Style was different: in one interview, Psy stated that he had made the song and music video targeting a Korean audience, not at all for overseas music fans (The New York Times 2012). It was the one and only local version of the video, not intended for global consumption, along with other derivative contents, namely parodies and flash mobs by ordinary people that elevated Gangnam Style to a global trend that ironically appealed to far more vast segments of the worldwide population than the usual K-pop fans.

Such an accidental occurrence reveals intriguing diversification and differentiation of the globalizing agencies and structures of today. The globalizing agencies that played the key role in the Gangnam Style phenomenon were not centralizing or consolidating forces - such as nation-states or multinational conglomerates - but a real, live, diffuse and diverse global audience: each individual and every Internet user who participated in the feast of the communicative process. A vast assemblage of viewers from various online platforms chose to become active co-creators in the Gangnam Style phenomenon by making parody videos and organizing flash mobs. These people were not merely passive consumers or observers. Cultural globalization driven by new media has distinctive mechanisms and characteristics, compared to the previous phases of media evolution led by mass media outlets, most notably radio and television broadcasters. New media enabled the active and direct participation of ordinary people in global creation and dissemination processes. This leads us into a discussion of hybridity.

\section{WHAT MAKES GANGNAM STYLE 'GLOBAL?' AN APPROACH FROM HYBRIDITY}

One of the main criticisms of hybridity is that it is a concept and a discourse mainly carried out by a privileged cosmopolitan elite (Friedman 1997; see Pieterse 2001 for a counter argument). However, today's manifestations of cultural hybridity grow increasingly out of grassroots power thanks to the development of digital technologies that connect, enable, and facilitate the participation of individuals around the globe. Despite all the existing limitations and inequalities, today's globalizing agencies and structures are more diversified 
than before, since digital technology has enabled ordinary people to actively participate in the process of globalization. It is not only nation-states or multinational conglomerates but also everyday Internet users who drive globalization (Shifman 2013). In this sense, ordinary people are more empowered to act more globally than ever, which results in the expansion of hybridity. Although hybridity is a contested concept, its emphasis is placed on the interplay between the global and the local. Well-known, overexposed examples of hybridity as the local reception of global trends range from various adopted versions of TV shows originating in the United States to diversified types of hamburgers and coffee drinks produced by global chains such as McDonalds and Starbucks. Yet, the Gangnam Style phenomenon is a case in which the global reception of the local happened; in fact, it became indicative of how boundaries between the global and local can blur.

Because of the concept's strong connection with post-colonial approaches, hybridity has often been understood with a focus on the mixture of race, ethnicity, and national cultures (Kraidy 2006). Similarly, we could argue that the Gangnam Style phenomenon manifests hybridity by emphasizing its marginal or peripheral "Korean" origin in the global hierarchy of the music industry (The Independent 2012; Jung 2014), explaining it as a mixture of Korean culture, American culture, and so forth. However, understanding hybridity simply as a mixture of culture often 'national' culture to be precise - has its limits when it comes to theorizing, as it begs the question of what is culture, whether it be local, global, or national, in the first place?

In this article, we embrace a broader perspective on the concept of hybridity that includes diverse intercultural mixtures not confined to racial, ethnic, and national cultures (Garcia-Canclini 1995; Pieterse 1994; Kraidy 2006). For Nestor Garcia- Canclini (1995), hybridity is crossing the borders of existing groups - as in conventional separations between the cultured and popular, between the public and private, and across cultures, styles, and genres. Likewise, as Marwan Kraidy has noted (2006, 5), because it involves "the fusion of two hitherto relatively distinct forms, styles, or identities, cross-cultural contact $\cdots$ is a requisite for hybridity."

According to Jan Nederveen Pieterse, who sought to provide a robust theory of hybridity with respect to culture, hybridization can be defined as "the ways in which forms become separated from existing practices and recombine with new forms in new practices." (Pieterse 1994; Rowe and Schelling 1991, 231) By "existing practices," Pieterse is referring largely to the nation-state as the primary, even privileged venue for political and social life, and by "new practices" he is referring to developments such as the emergence of online social networks and transnational venues for conversation, collaboration and contestation. In Pieterse's view, the hybridity perspective problematizes the reification of culture and the salience of existing boundaries. The reification of culture 
presumes purity of culture, which nullifies the aspects of social construction and historical processes that were involved in the complex creation and evolution of culture (Pieterse 1994). Hybridity is a notion against the concept of purity and instead underscores negotiation and interaction across different categories.

Hybridity, then, can effectively rebut criticism for "being a dependent notion" or for "skipping over questions of power and inequality" (Pieterse 2001, 225). Hybridity strategically problematizes trenchant beliefs throughout modern history in the primacy of purity and fixed boundaries by interpreting (and downgrading) these factors as existing assumptions that often turn out to be illusory in practice. This critical position provokes further questions regarding inequality, as power relations are fundamentally grounded on levels of hierarchy demarcated by boundaries (Pieterse 2001, 225). Therefore, in order to use hybridity as an analytical tool, we have to understand hybridity in the specific contexts in which it functions.

In this regard, hybridization refers to "a cross-category process" (Pieterse 1994, 171-172) that transgresses categories such as nations, ethnicities, status groups, religion, classes, and genres. In other words, hybridization must contain incongruous elements. Although Pieterse emphasizes the presence of asymmetric elements as signifying hybridity, we see the concept of asymmetry as setting the bar too high in identifying any presence of hybridity, especially given that this could be taken to presume neatly symmetric elements in the absence of hybridity. We maintain that incongruity, rather than asymmetry, can more readily capture the actual processes of hybridity. In addition, hybridity has to function as part of a power relationship between the center and the margins, as well as between hegemony and minority, and, in some instances, fantasy and reality, blurring any preconceived hierarchical relationships.

Provided with this specific context and function of hybridity, the limitations of an analysis of hybridity that goes no further than non-critical description of cultural mixing become clearer. More important, if analysis on hybridity concentrates on the search for various seemingly original 'cultures' - Korean, Argentinean, Indonesian and so forth - in an effort to identify and to prove hybrid nature, it paradoxically cannot avoid reifying each 'culture'. In addition, with an approach that emphasizes the original ethnic, racial, or national culture, the endeavor of hybridity analysis can fall into the fraught position of defining, in deceptively binary terms, 'global culture' and 'local culture', which in turn calls for reification once again through the process of clarifying the essence of the 'local culture' in relation to a more abstract 'global culture'. After all, one trenchant criticism of hybridity notes that "all cultures are always hybrid" (Werbner 1997).

Therefore, we choose not to interpret hybridity as a mere mixture of national cultures but instead, emphasize its functional aspect of mixing, crossing and fusing incongruous categories. We think it is less important for researchers to 
pursue the question of whether Gangnam Style is Korean, Eastern, Western or amorphously global. Above all, what makes Gangnam Style hybrid is not the way it mixes electronic music with mythical Korean rhythms or sentiments but how it contains numerous incongruous elements that cut across supposedly binary categories and cultural norms.

The concept of hybridity as developed by Pieterse can be applied to explain Gangnam Style and its derivative contents. In terms of power relations, Gangnam Style itself contained satire directed straight at the heart of contemporary Korean society, insinuating subversion toward the hegemony of the Gangnam district over other districts in the city of Seoul. Gangnam stands for high-end restaurants, overpriced cafes, luxurious boutiques, and other exclusive services, and the Gangnam lifestyle has become a desirable standard, even a dream for citizens in Seoul. However, the Gangnam Style video portrays the Gangnam lifestyle as vulgar and pretentious. In this sense, it indicates a transgression of district hierarchy within Seoul by reinterpreting the symbolic meaning of Gangnam.

In terms of cross-category processes, central to the definition of hybridity noted earlier, several varied forms of incongruity are manifest in Gangnam Style. First, incongruity can be observed between Gangnam as a territorial space (the district in southern Seoul) and Gangnam as a cultural representation that sets the stage for Gangnam Style. While Gangnam the district is seen as the most trendy area in Seoul, Gangnam Style the video is full of random, incompatible and downright silly elements that ultimately mock the symbolism of Gangnam the district, tweaking its pretensions. Second, various forms of incongruity between the song lyrics and the video images can be detected. One such example is shown at the beginning of the music video, in which Psy walks with two women through a stable with paper debris (i.e. crumpled up newspapers) flying in their faces. At this point, the lyrics say "a girl who is warm and human during the day, a classy girl who knows how to enjoy the freedom of a cup of coffee." There is a glaring mismatch between the words and the pictures. Third, there is incongruity within the lyrics: for instance, "A girl who looks quiet but plays when she plays" and "A girl who covers herself but is more sexy than a girl who bares it all" do not really make sense. Such lyrics evoke two opposite ideals of femininity. The fourth and most important incongruity is within the video images. Since the vast global audience did not understand Korean, the significance of images is paramount, and incongruous images abound in Gangnam Style. Psy appears in a fancy formal suit with a bow tie, but his dance-moves, his gestures, the places he visits, and his overall manner do not go along with his fashion. Incongruous elements also show up with the supporting cast: hip younger generations and frumpy older generations are presented at the same time dancing together; the global urban-scape and particular local-scape are mixed; and throughout the video, the gorgeous and the hideous are mixed along with upscale and downscale slices of urban life. Hence 
we think it is less important to pursue the question of whether Gangnam Style is Korean, Eastern, or Western. Above all, what makes Gangnam Style hybrid is not the way it mixes electronic music with mythical Korean rhythms or sentiments but how it contains numerous incongruous elements that cut across supposedly binary categories.

\section{WHEN GANGNAM STYLE BECAME A 'PHENOMENON' : HYBRIDITIES IN DERIVATIVE CONTENT}

The video trail of parodies and flash mobs that virtually circumnavigated the globe in the latter half of 2012 amounted to an extended global celebration that generated, prolonged and magnified the excitement of the Gangnam Style phenomenon. Such derivative contents and the many hybrid elements within them serve to illustrate how the original music video was highly suitable for this global response. While derivative contents cut across parodies, reaction videos, and flash mobs, parodies were the most prevalent and popular (Jung 2014), and likewise, our focus is mainly on parodies.

Both the mundane aspects and the absurd elements of the original video were ripe for transposition; many scenes in the original Korean video combined mundaneness and absurdity in ways in which a global audience could easily relate, with easily recognizable fragments of English helping here and there. This mundane absurdity amounts to yet another form of hybridity, by means of asymmetry, in the Gangnam Style video. From Psy's scene on the toilet seat in which he calls out "Do you know what I'm saying?" (for many viewers, the answer was 'no') to his refrain "Ey, sexy lady!" to the horse dancing scenes in buses, barns, parking garages and subway stations (all rather lower-class venues that fly in the face of the upper-class assertions in the original song lyrics), the mundane absurdity that filled the original video carried a universal appeal and was quite easy to replicate and redeploy in all sorts of directions. In addition, since the video often showed fairly generic urban landmarks and cityscapes around Seoul, it was easy to shoot videos elsewhere in the same kinds of urban settings: playground, carousel, gym, bus, riverfront, elevator, parking garage, subway, pool/sauna, and street intersection. Some parodies use the original song (the audio) cut to fresh video; others presented altered lyrics while replicating the scenes from the original video; and still others crafted entirely new video sequences tailored mainly to the lyrics of the parody rather than the original song.

By redeploying in new directions the underlying rhythm of the song and the images of the video, the parodies that make up this global response to Gangnam Style can be segmented into several categories, which we identified after watching the most heavily viewed parodies of Gangnam Style on YouTube and analyzing and differentiating their characteristics: (1) replication of the 
original video in a different setting (2) satire targeting specific individuals as well as organizations and collective identities (3) videos seeking to raise public consciousness of a particular issue or problem (4) videos by artists and organizations seeking to gain global visibility for its own sake. These four categories, which often overlap in the individual videos, represent the main approaches taken by the individuals and groups that posted videos online in response to Gangnam Style. These categories (see Table 4) also allow us to draw out the various elements of hybridity in the individual videos.

\section{TABLE 3. CATEGORIZATIONS OF PARODY VIDEOS}

\begin{tabular}{|c|c|c|}
\hline Category & Video title & Characteristics \\
\hline Replication & $\begin{array}{l}\text { - Kazakh Style and other city-based videos } \\
\text { - Gangnam Style Indonesia } \\
\text { - Azonto Gangnam Style }\end{array}$ & $\begin{array}{l}\text { Videos kept the Korean language and created } \\
\text { similar images to the original video alongside } \\
\text { Psy's Korean soundtrack }\end{array}$ \\
\hline Satire & $\begin{array}{l}\text { - Eastern Europe Style } \\
\text { - Middle Eastern Style } \\
\text { - Pyongyang Style } \\
\text { - Jewish Style } \\
\text { - Working Christian Style } \\
\text { - Catho Style } \\
\text { - Mitt Romney Style }\end{array}$ & $\begin{array}{l}\text { Videos skewered group identities of all sorts - } \\
\text { regional, religious, political - by highlighting } \\
\text { (sometimes in excess) stereotypes and } \\
\text { caricatures often associated with these } \\
\text { identities. }\end{array}$ \\
\hline Advocacy & $\begin{array}{l}\text { - Gangnam for Freedom } \\
\text { - Bomba Style / - Vegan Style } \\
\text { - Arabic Parody Ganin Style }\end{array}$ & $\begin{array}{l}\text { Videos tried to raise public awareness of key } \\
\text { issues. }\end{array}$ \\
\hline Promotion & $\begin{array}{l}\text { - Open Condom Star } \\
\text { - Hot Dog Condom Style } \\
\text { - Gangnam Style Mom } \\
\text { - Nasa Johnson Style } \\
\text { - MIT Gangnam Style and other university } \\
\text { and school videos }\end{array}$ & $\begin{array}{l}\text { Videos sought to increase global visibility of } \\
\text { either individual artists or organizations }\end{array}$ \\
\hline
\end{tabular}

Taking replication, for starters, many videos kept the Korean language and simply created similar images to the original video to showcase over Psy's Korean soundtrack. Cities on every continent have playgrounds in apartment complexes, riverfronts lined with concrete towers, women who exercise in public parks, and people fated to meet and fall in love through chance encounters on public transportation. Therefore the most commonly produced parody videos were set in cities such as London, Sydney, Hong Kong, Krakow, Shanghai, Chicago, New York, and Paris. One such copycat video, Kazakh Style, includes all the above scenes from the original video shot in Kazakhstan's capital of Astana. In its mimicry, Kazakh Style elevates (either intentionally or inadvertently) the mundane absurdity of the original Gangnam Style video to universal elements of daily contemporary urban life. Other parodies simply 'bring home' the eccentricities of the original video to their particular local audiences. One parody from Indonesia, titled Gangnam Style Indonesia, features a version of the song in the country's native language and shows many of the same scenes but 
with some key differences, such as a woman who uses a tennis racket to push down the Psy lookalike's face as he sits in a lounge chair in the opening scene, pregnant women doing yoga exercises, and the final bit with Psy and Hyunah lookalikes in a wine bar rather than a subway. Likewise, a parody titled Azonto Gangnam Style brings home the original video to an audience in Ghana: street scenes in its capital city, Accra, and a mix of English and African tribal languages, with a small group of participants enthusiastically dancing and copying scenes such as the elevator sketch. Such videos also illustrate how "Eh, sexy lady!" quickly became a universal refrain across language differences.

Secondly, satirical videos in response to Gangnam Style skewer group identities of all sorts by highlighting (sometimes in excess) stereotypes and caricatures often associated with these identities. One such video, Eastern Europe Style, invokes a slang word for 'prostitute' for its punchline "Hey, sexy Kurvas! Work, work, work, work, drink, fight Eastern Europe Style!" This parody seemed to overstate the extent of poverty in Eastern Europe as well as the habits and foibles of the population of an entire region. Another parody video, Middle Eastern Style, portrays slack young men living with their mothers and staying out all night.

Not surprisingly, North Korea is the focus of multiple parodies in response to Gangnam Style. The makers of Pyongyang Style, for example, simply edited together video images of North Korea - real archive video, not video shot specifically for the parody - set to the original music of Gangnam Style. When viewed in juxtaposition with the total range of Gangnam Style parody videos and flash mobs - and after watching so many people dancing freely in dozens of public squares - it is chilling to watch Kim Il Sung Square in Pyongyang filled with phalanxes of soldiers marching in absolute unison. Indirectly, these kinds of images set to Gangnam Style's freewheeling melody remind us of North Korea's hyper-totalitarian state as an anomaly in today's global landscape and the country's status as an outlier in today's interconnected world. The images of state oppression and control serve as an effective, sobering and also - related to our view of hybridity - incongruous counterpoint to images and sounds of freedom. In a sense, Pyongyang Style allows the North Korean regime to parody itself simply by showing real life in the North Korean capital (by far the most advantaged city in North Korea) under its control. The juxtaposition of the real and the fictional in the North Korea videos - a blend of actual raw video footage and totally staged satire, often playing to stereotypes - provides yet another example of the hybridity in the derivative contents within the Gangnam Style phenomenon.

The same applies in various parody videos focused on religious groups a mixed bag of videos that cut across the sardonic and the sincere. The lead singer of Jewish Style, a (white) man who looks nothing like Psy, prays for a "smaller 
nose" and features his unknown relatives and friends of the family throwing money his way at his bar mitzvah: "Hey, sexy rabbi!" is the refrain. Instead of ironic self-deprecation, Christian Style shows an earnest minister from the Cold Lake Community Church, located in the Canadian midwestern province of Alberta, using the catchy packaging of Gangnam Style to make a sermon more appealing. Lines include "We love Jesus Christ, and we want the world to know it," and the refrain captures the sincerity of the parody, as it shows actors helping an elderly woman cross the street: "Hey, let's help that lady! Working Christian Style!" The rather incongruous injection of this earnest community service ethic into the mundane absurdity of the original Gangnam Style packaging serves as yet another kind of hybridity in the larger Gangnam Style phenomenon. The video also placed a church pastor into the global limelight who otherwise would have remained highly obscure. The public response was mixed: "I love it - praise the Lord!" said one commenter, while another posted: "Overkill, poor lady."

Catho Style, meanwhile, operates somewhere between Jewish Style and Christian Style, combining bits of sincerity and self-mocking humor - a balancing act that in itself lends hybridity. Filmed in Paris and aptly using Notre Dame and the carousel outside Hotel de Ville, the parody suitably combines elements of the original Gangnam Style video with shots of both Catholic ritual and Catholic stereotypes; the parody combines reverence, irreverence and tackiness to render an odd and incongruous set of hybridities. The film sums up Catholics as praying the rosary, eating fish (on Friday), partying hard - and then going to Confession; the re-enacted bus scene and explosion scene are juxtaposed with people blessing themselves; the exercise scene shows the women holding Bibles; the elevator scene features a man wearing a cassock; and, to no surprise, a man wearing what looks like a priest's collar leads the jovial dancing with a larger group toward the end of the video. Instead of "Eh, sexy lady! Oppa Gangnam Style," the key phrase becomes "Hey, holy lady! A-a-a-a-amen!"

Despite all the warnings to avoid discussing religion and politics in dinner conversations, the parody videos focus heavily on both. One political parody must be singled out for its originality and impact: Mitt Romney Style was posted online four weeks before the 2012 United States presidential election and lampooned the Republican nominee challenging Barack Obama. From the start of the song, the stand-in Romney exuded a thoroughly obnoxious air that - although over the top - captured the essence of the 'real' Romney following a series of campaign gaffes and slips, especially following the disclosure of his now infamous September 2012 statement disparaging the 47 percent of Americans who pay no annual income tax.

The lyrics that made up the first verse of Mitt Romney Style smack the viewers with such direct vulgarity that it sets up the more understated elements of vulgarity that the producers convey and attribute to Romney in the remainder of 
the video: "I got a horse in the Olympics girl, but I don't even watch 'em. In and out of tax loopholes 'cause I'm so fuckin' awesome. Bitch it's Friday night so we be benefit hoppin' check my con-spic-u-ous consumption...". While this parody left out the bus scene, it included the explosion scene - blowing up piles of money, of course - and transposed Psy's "Eh, sexy lady!" to "Hey, wealthy ladies!" Even the elevator, sauna and toilet scenes were easily transposable from Psy to Romney: "Baby baby. I got butlers just to wipe me. You know what I'm sayin'!" All this is not to overstate the quality or impact of Mitt Romney Style but does show how Gangnam Style parodies managed, at times, to communicate substantive issues to the public in a humorous way, and that the empty shell of the underlying beat of the original music and video images - with all their asymmetries - could be easily transposed in the parodies to produce a completely different satire targeting individuals and issues in a completely different country. Mitt Romney Style shows with exceptional clarity why the original Gangnam Style easy replicability and transferability into parody indeed served as a central element of its wide global appeal.

Thirdly, other parodies intertwine fun and games with raising public consciousness - asymmetrically combining silly and serious to make specific points. Supporters of artist and Chinese dissident Ai Wei Wei, led by the United Kingdom chapter of Amnesty International, produced the video "Gangnam for Freedom" that included Anish Kapoor (a British-Indian sculpture) and staffers at art museums around the world doing the famed horse dance; the video ended with a list of people either killed or persecuted by governments cracking down on freedom of expression. This video followed a parody that Ai himself made, which showed him horse-dancing and, at one point, waving handcuffs, thereby juxtaposing incongruous images of freedom and captivity; this was taken offline by China's censors shortly after its posting but subsequently made its way back to YouTube. The threat of nuclear weapons, meanwhile, served as the key global issue of interest in Bomba Style - which imitates Psy while carrying a serious message, beneath all the images and seemingly frivolous phrases such as "Hey, sexy missile - oppa bomba style!" Likewise, a parody titled Vegan Style makes serious points about the possible ethical credibility and health benefits of a vegan diet although it is hard to digest portions of the lyrics with a straight face, such as this rather grotesque redeployment of the toilet seat scene in the original video: "Now that I'm vegan, my shit smells better! I'm more healthy, ecologic and even happier!" Still, Vegan Style met a favorable reception in the online universe with nearly 1.4 million YouTube views as of May 2015 and triple the ratio of 'likes' to 'dislikes'.

A call to overcome bigotry, meanwhile, took center stage in Arabic Parody Ganin Style, set in New York City and effectively creating these lyrics to fill the second verse of the song: "There's so much hate, even Asians, blacks, 
Latinos, they get this hate; don't you remember that we are all the same. I said it at the beginning of this song, don't be insane!" The producer of the video, an Egyptian who lives in New York, posted his work on YouTube under the name "arewefamousnow" and eventually his video did become famous with 5.6 million views. He later made an "Arab Parody" of Psy's Gentleman that garnered 5.1 million views on YouTube. These parodies also provide a kind of hybridity by combining serious political and ethical points with ridiculous words and images.

Other artists acted simply to gain global visibility while having fun. One video parody poking fun at the original song's lyrics has the punchline, Open Condom Star, imagining how the Korean language lyrics (such as "Oppa Gangnam Style!") sound to English-speaking ears. The artist in this case, who goes by the name Chad Wild Clay, earned his 9.8 million YouTube viewers (as of June 2015) purely through his wits; although he does parodies of lots of songs, this is the one that made him famous. Yet another parody of the song's lyrics, based on the same concept, used the catchphrase: "Hot Dog Condom Style!" In this way, the arbitrary and incongruous transposition of the original audio content of Gangnam Style from (often nonsensical) Korean to (even more nonsensical English) offers still another example of hybridity. Another example is Gangnam Style Mom video: a hip-hop dance instructor and Korean American Mike Song and his mother, Laura Song, together became famous and landed a television appearance on The Ellen DeGeneres Show in New York after they posted a simple video showing the two of them combining dancing, hand motions and deadpan expressions. Their video went viral not because of Mike Song but because of his 'Mom', Laura Song; this middle-aged Asian woman dancing along to Gangnam Style caught the public's imagination with surprise, breaking the boundaries of old and young, liberal and conservative, and thereby producing a meaningful hybridity.

Not only individuals, but also organizations and institutions - even national bureaucracies - sought the global limelight by taking part in the Gangnam Style phenomenon. In the United States, a parody video by the National Aeronautics and Space Administration (NASA) gained 5.8 million views and 6 million 'likes' on YouTube for its parody video full of hybrid elements incongruously mixing hard sciences and humorous dances. Scientists in a laboratory who seem to be serious and rational suddenly shout out "Oppa Gangnam Style!" with dance moves that shatter the boundaries of expected social roles and contextual norms. Similar parodies from organizations flourished at universities where creative students abound. Students at the Massachusetts Institute of Technology in Cambridge produced the most colorful and elaborate parody on a university campus in response to Gangnam Style. The students kept the Korean music soundtrack and tailored their own distinctive scenes effectively and strikingly to their campus community. Renowned MIT professors Donald Sadoway (chemistry) 
and Eric Lander (biology) make appearances with the Psy lookalike - with Lander stepping into dance in his lecture hall.

The icing on the cake of the MIT parody, placed just after Psy's line "Do you know what I'm saying?" is the appearance of renowned professor Noam Chomsky, vigorous as ever at age 83 at the time the parody was recorded. The video clip first shows Chomsky taking a long sip of tea and then looking straight into the camera to say, with a straight face: "Oppa Chomsky Style." Some online commenters said they tuned into MIT Gangnam Style just to see the Chomsky clip; the parody ends on a humorous concluding note with Sadoway returning to his office to find the Psy lookalike doing the horse dance there. The organizers of the video were interested mainly in having fun while also giving MIT an even higher profile with the large global audience that became readily available, ripe for the picking, after Gangnam Style went viral. Closer to the heart of our argument, the video also provided yet another source of hybridity by showing normally serious scholars freely acting out key phrases, gestures and dance moves from the original Gangnam Style video. Taken together, these combined elements of mundaneness and absurdity played into the extended global celebration that marked the Gangnam Style phenomenon.

\section{CONCLUSION}

The global reception of Gangnam Style instantly evolved to the global production of the Gangnam Style phenomenon, with its crescendo of parodies, flash mobs and street performances. This process created a "community of sentiment," in Arjun Appadurai's parlance, with a myriad of assemblages in cities around the world and also virtually in cyberspace. Although these communities of sentiment were transient and fleeting, the mobilizations inspired by Gangnam Style proved meaningful and memorable as diverse groups of people gathered together, often spontaneously, to sing, dance, laugh, vent and exchange ideas, as evidenced in the videos themselves as well as the online comments left behind for each one. Collective imagination became paramount in this community of sentiment, as each production required plenty of creative, 'outside the box' thinking to conceive and then orchestrate. Each parody required decisions not only about its planned topic and content but also regarding which fragments of the original Gangnam Style video were best suited for transposition into the parody, and at least implicitly, how fragments of particular cultural norms and identities would then manifest themselves in the resulting videos. The fruits of these individual and collective acts of imagination and remain visible for all to see in the trail of videos left behind indefinitely, if not permanently, by each active co-creator within the global conversation that resulted.

What kind of collective imagination emerged from the Gangnam Style 
phenomenon? Admittedly, the endeavor of redeploying "Hey, sexy lady!" into infinite spinoff phrases isn't exactly the same kind of imagination that brings together transnational activists in the environmental movement, the peace movement, the human rights community, and so forth to campaign for change and, on occasion, hold coordinated rallies in dozens of cities, often on the same day. And yet, several response videos to Gangnam Style did try to raise awareness of selected issues and articulate hope for a better world. More central to the collective imagination in this "community of sentiment" (Appadurai 1996) was the overriding emphasis placed on freedom and free expression in signifying how individuals and their respective associations can mobilize to shape and advance a global cultural public space. This legacy ties into the political relevance of the Gangnam Style phenomenon as well as the central role of hybridity. The mixing, recombining and transgressing of fixed categories and boundaries; the continual blurring of reality and fiction, fact and fantasy, earnest and ridiculous, serious and silly; and the incongruous images and mundane absurdity of both the original Gangnam Style video and the subsequent parodies, all served as defining characteristics of this specific global cultural public space that flourished in the fall of 2012. In the end, it was through these recombinations and transgressions that the Gangnam Style phenomenon most effectively asserted, at times directly and in other cases more subtly, the primacy of freedom of expression as an important core democratic principle to be pursued and cherished worldwide.

\section{REFERENCES}

Appadurai, Arjun. 1996. Modernity al large: cultural dimensions of globalization. Minneapolis: University of Minnesota Press.

Boyd-Barrett, O. 1977. "Media Imperialism: Towards an International Framework for the Analysis of Media Systems". In Mass Communication and Society, Edited by: Curran, J., Gurevitch, M. and Woollacott, J. 116-135. London: Edward Arnold.

Canclini, Néstor García. 2005. Hybrid cultures: Strategies for entering and leaving modernity. Minneapolis: University of Minnesota Press.

Cho, Chung-un. 2012. "PSY's "Gangnam Style" video draws over 130milion view from 220 countries," in The Korean Herald, last modified September 11, 2012, accessed June 28, 2017, http://www.koreaherald.com/view.php? $\mathrm{ud}=20120911001159$

Cho, In-Hee and Yeo-kwang YOON. 2013. "A Study on the Youtube Far Reaching Effects Having Impact on Korean Wave - Focused on Singer PSY Syndrome." Korean Entertainment Industry Journal 7(2): 9-18.

Cho, Wu-suk. 2012. "Riding the Korean Wave From "Gangnam Style" To Global 
Recognition.” Global Asia 7(3):35-39

Cover Story. 2012. "How the K-Pop Breakout Star Harnessed the Power of YouTube, SNL and More to Become Music's New Global Brand," in BillBoard, last modified November 2, 2012, accessed July, 28, 2017, http:// www.billboard.com/articles/columns/k-town/474456/psys-gangnam-stylethe-billboard-cover-story

Fisher, Max. 2012. "Gangnam Style, Dissected: The Subversive Message Within South Korea's Music Video Sensation," in The Atlantic, last modified August 23, 2012, accessed July 26, 2017, https://www.theatlantic.com/international/ archive/2012/08/gangnam-style-dissected-the-subversive-message-withinsouth-koreas-music-video-sensation/261462/

Giddens, Anthony. 1991. Modernity and Self-identity: Self and Society in the Late Modern Age, California: Stanford University Press.

Giddens, Anthony. 2013. The consequences of modernity, California: John Wiley \& Sons.

Harvey, David. 1989. The condition of postmodernity, Oxford: Blackwell.

Hong, Seok Kyung. 2013. Hallyu as a Digital Culture Phenomenon in the process of globalization, Seoul: Hanul Academy.

Jenkins, Henry. 2006. Convergence culture: Where old and new media collide, New York: NYU press.

Jung, Ji-sup and Ji-hyeYang. 2012. "8 million crowd in front of Seoul City Hall, horse-riding dancing with the world (Seoulsicheong ap 8manmyeong, segyewa hamkke malchum chuda)," in News Chosun, last modified October 5, 2012, accessed July 28, 2017, http://news.chosun.com/site/data/html_dir/ 2012/10/05/2012100500253.html?Dep0=twitter\&d=2012100500253

Jung, Sun and Doobo Shim. 2014. "Social distribution: K-pop fan practices in Indonesia and the 'Gangnam Style'phenomenon." International Journal of Cultural Studies 17(5): 485-501.

Jung, Soo Keung. 2014. "Global Audience Participation in the Production and Consumption of Gangnam Style." (Ph.D. dissertation, Georgia State University). Kim, Jin. 2012. "The institutionalization of YouTube: From user-generated content to professionally generated content." Media, Culture \& Society 34(1): 53-67.

Korte, Gregory. 2012. "Romney: Obama voters "believe they are victims," in USA Today, last modified September 17, 2012, accessed July 20, 2017, http://usatoday 30.usatoday.com/news/politics/story/2012/09/17/romneys-47-remark/5779 $7246 / 1$

Kraidy, Marwan. 2006. Hybridity, or the cultural logic of globalization, Philadelphia: Temple University Press.

Kuwahara, Yasue (Ed.). 2014. The Korean wave: Korean popular culture in global context. New York: Palgrave Macmillan 
Kwon, Hye Jin. 2012. "Psy's concert at Seoul City Hall, the most viewed live concert in the world (Psy Seoul gongyeon, jeon segye choedasicheong live concert)," in Yonhapnews, last modified December 26, 2012, accessed July 24, 2017, http://www.yonhapnews.co.kr/bulletin/2012/12/26/0200000000 AKR20121226068200017.HTML

Lee, Sangjoon and Abe M. Nornes (Ed.). 2015. Hallyu 2.0: The Korean Wave in the age of social media. Ann Arbor: University of Michigan Press.

Lee, Kyuho. 2012. "Meme and Cultural Diffusion in Social Media: Focused on PSY's "Gangnam Style" Sensation," Asia Digital Art and Design Journal: 94-97.

Lee, C. Seungeun and Yasue Kuwahara. 2014. "Gangnam Style as format: When a localized Korean song meets a global audience." Korean Popular Culture in Global Context: 101-116.

Lie, John. 2012. "What is the K in K-pop? South Korean popular music, the culture industry, and national identity." Korea Observer, 43(3): 339-363.

Murdock, Graham. 2006. "Cosmopolitans and conquistadors: Empires, nations and networks." In Communications Media, Globalization and Empire edited by Boyd-Barrett, Oliver, 17-32. Bloomington: Indiana Press.

Nye, Joseph. and Youna Kim. 2013. "Soft power and the Korean wave." In The Korean wave: Korean media go global, edited by Youna Kim, 31-42. London: Routledge.

Park, Jung-Sun. 2013. "Why 'Gangnam Style' isn’t hallyu style." Global Asia 8(3): 84-88.

Pieterse, J. Nederveen. 1994. "Globalisation as hybridization." International Sociology 9(2): 161-184.

Pieterse, J. Nederveen. 2001. "Hybridity, so what? The anti-hybridity backlash and the riddles of recognition." Theory, Culture \& Society, 18(23): 219-245.

Robertson, Roland. 1992. Globalization: Social theory and global culture. Thousand Oaks: SAGE Publications.

Russell, Mark. 2012. "The Gangnam Phenom: A South Korean video is making waves on the Web. But the West is actually late to the party," in Foreign Policy, last modified August 23, 2012, accessed July 28, 2017, http://www. foreignpolicy.com/articles/2012/09/27/the_gangnam phenom

Ryzik, Melena. 2012. "His Style is Gangnam, and Viral Too," in The New York Times, last modified October 11, 2012, accessed July 25, 2017, http://www. nytimes.com/2012/10/14/arts/music/interview-psy-the-artist-behind-gangn am-style.html?_r=0

Schiller, Herbert. I. 1971. Mass communications and American empire. Boulder: Westview Press

Sherwin, Adam. 2012. "Gangnam Style isn't a one-off - Major music industry report says future pop sensations will be YouTube-driven globalised acts 
from Asia and South America," in Independent, last modified November 12, 2012, accessed July 24, 2017, http://www.independent.co.uk/arts-enter tainment/music/news/gangnam-style-isnt-a-oneoff--major-music-industryreport-says-future-pop-sensations-will-be-youtubedriven-globalised-acts- $f$ rom-asia-and-south-america-8307206.html

Shifman, Limor. 2013. Memes in digital culture. Cambridge: MIT Press.

Shim, Doobo. 2006. "Hybridity and the rise of Korean popular culture in Asia." Media, culture \& society 28(1): 25-44.

Steger, Manfred. B. 2008. The rise of the global imaginary: Political ideologies from the French revolution to the global war on terror. Oxford: Oxford University Press.

Tomlinson, John.1991. Cultural imperialism. Hoboken: John Wiley \& Sons.

Tomlinson, John.1999. Globalization and culture. Chicago: University of Chicago Press.

Tunstall, Jeremy. 1977. The Media are American, Anglo-American Media in the World. London: Constable.

Walsh, John. 2014. "Hallyu as a government construct: the Korean Wave in the context of economic and social development," In The Korean Wave edited by Yasue Kuwahara, 13-31. New York: Palgrave Macmillan.

Werbner, Pnina. 1997. "Essentialising essentialism, essentialising silence: ambivalence and multiplicity in the constructions of racism and ethnicity," in Debating Cultural Hybridity edited by Pnina Werbner and Tariq Modood, 226-254. London: Zed Books. 